\title{
Treating Adults with Hodgkin Lymphoma in the Developing World: a Hospital-Based Cohort Study from Armenia
}

\author{
Armen Avagyan, Samvel Danielyan, Astghik Voskanyan, Lilit Sargsyan, Lusine \\ Hakobyan, Davit Zohrabyan, Liana Safaryan, Lilit Harutyunyan, Samvel \\ Bardakchyan, Samvel Iskanyan, Samvel Arakelyan, Gevorg Tamamyan*
}

\begin{abstract}
Background: With advances in diagnostics and treatment approaches, patients with Hodgkin's lymphoma (HL) in developed countries can nowadays expect to have excellent outcomes. However, information about the characteristics and outcomes in the developing world is very scarce, and this is important given the fact that there are several reports about differences of disease characteristics depending on geographic location and the development level of the country. Materials and Methods: In this retrospective study we assessed the features of 36 adult ( $\geq 18$ years old) patients with HL and their diagnosis and treatment and outcomes in the Clinic of Chemotherapy of Muratsan University Hospital of Yerevan State Medical University, Armenia, between 20082014. Results: All patients had classic HL and among them 19 (53\%) had nodular sclerosis subtype, 8 (22\%) mixed cellularity and $9(25 \%)$ lymphocyte-rich. $16(44.5 \%)$ patients were at stage II, $13(36 \%)$ stage III and 7 (19.5\%) stage IV. Median follow-up time was 24.5 months (range 1-71 months) and during the whole followup period only two relapses (early) were documented and there were no deaths. Twenty-three $(64 \%)$ patients received a BEACOPP (bleomycin, etoposide, doxorubicin, cyclophosphamide, vincristine, procarbazine, and prednisone) regimen, and $13(36 \%)$ ABVD (doxorubicin, bleomycin, vinblastine and dacarbazine) regimen. A total of $25(69.5 \%)$ patients received radiation in addition to chemotherapy. Conclusions: Although the number of patients involved in the study is small and the median follow-up time was just two years, this retrospective study shows that treatment of HL can be successfully organized in a resource-limited setting.
\end{abstract}

Keywords: Hodgkin's lymphoma - developing country - Armenia - ABVD - BEACOPP

Asian Pac J Cancer Prev, 17 (1), 101-104

\section{Introduction}

Over the last decades with the advancements in diagnostics and treatment approaches, many cancer types can be expected to have excellent outcomes. Hodgkin lymphoma (HL) or Hodgkin's disease, first described by the British pathologist and reformer Thomas Hodgkin, today with the use of chemo- and radiotherapy can reach cure rates of up to $80-90 \%$ (Geller and Taylor, 2013; DeSantis et al., 2014).

While in many other cancer subtypes today's medical and scientific efforts mostly are directed to find better treatments and increase the survival, in HL the concept of "cure" is widely accepted idea, especially for the patients with early stage disease, and currently HL researchers are concentrating their research mainly on how to decrease the late effects of the treatment, while keeping the excellent survival rates. But this all story is mostly about developed countries like United States or Germany, and much less is known about the features and outcomes of patients diagnosed and treated in developing world, given also the fact that there are several reports about differences of disease characteristics depending on geographic locations and the development level of the country (Macfarlane et al., 1995).

Recently, few studies were published from African and South Asian regions examining the clinico-pathological characteristics and the outcomes of HL patients (Dinand and Arya 2006; Siddiqui et al., 2006; Olu-Eddo and Omoti 2011; Hessissen et al., 2013; Baharvand and Mortazavi 2014; Fadhil, Al-Nueimy, and Lazim 2014; Sughayer et al., 2014; Sherief et al., 2015), however the information about characteristics and outcomes of HL from South Caucasian region is lacking, which was one of the main reasons to conduct this retrospective study. In this study we describe the features of adult patients with Hodgkin lymphoma and their outcomes, diagnosed and treated at our clinic in Armenia during recent years. 


\section{Materials and Methods}

The data of adult patients ( $\geq 18$ years old) with newly diagnosed Hodgkin lymphoma, diagnosed and treated at the Clinic of Chemotherapy of Muratsan University Hospital of Yerevan State Medical University between 2008 - 2014 were retrospectively collected and analyzed. The data included demographic information, clinical and laboratory features at diagnosis, staging, treatment, follow-up, as well as information on whether patients received treatment covered by the government (free) or paid out-of-pocket. The diagnosis was confirmed by the histo-pathological and immunophenotypic characteristics (Harris, 1999), and Ann-Arbor staging system was used for the clinical staging (Carbone et al., 1971; Lister et al., 1989).

National Comprehensive Cancer Network (NCCN) Clinical Practice Guidelines in Hodgkin Disease/ Lymphoma were used for diagnosis, treatment decisions, response criteria and follow-up ("NCCN Clinical Practice Guidelines in Oncology. Hodgkin Disease/Lymphoma" 2008). Patients received either 4-6 cycles of ABVD (doxorubicin, bleomycin, vinblastine and dacarbazine) regimen or 6-8 cycles of BEACOPP (bleomycin, etoposide, doxorubicin, cyclophosphamide, vincristine, procarbazine, and prednisone) regimen with/or without radiation therapy ("NCCN Clinical Practice Guidelines in Oncology. Hodgkin Disease/Lymphoma” 2008).

\section{Results}

36 adult patients (median age 28 years, range 18-72), from which 16 (44\%) males and 20 (56\%) females, were diagnosed and treated at our clinic during mentioned period of time. Based on histo-pathological and immunophenotypic characteristics, all patients had classic Hodgkin lymphoma and among them 19 (53\%) patients had nodular sclerosis subtype, $8(22 \%)$ patients mixed cellularity and $9(25 \%)$ patients lymphocyte-rich. $16(44.5 \%)$ patients were at stage II, 13 (36\%) patients stage III and 7 (19.5\%) patients stage IV. At presentation $34(94.5 \%)$ patients had lymphadenopathy, and cervical/ supraclavicular (30 patients; $81 \%$ ) and mediastinal (19 patients; 53\%) nodes were the most commonly involved. 14 (39\%) patients presented with fever, 7 (19.5\%) with night sweating, 2 (5.5\%) patients with skin rash, $7(19.5 \%)$ presented with dyspnea and $2(5.5 \%)$ with bone pain. None of the patients had affected bone marrow.

Median follow-up time was 24.5 months (range 1-71 months) and during the whole follow-up period only two relapses (early) were documented and there was no death. $23(64 \%)$ patients received BEACOPP regimen, and 13 (36\%) patients ABVD regimen; from 13 patients who received ABVD regimen 12 of them were with stage II disease. $25(69.5 \%)$ patients received radiation in addition to chemotherapy. During chemotherapy the most common complication was leukopenia $\sim 58 \%$, and G-CSF was delivered in those patients.

Both relapsed patients were young - 28 and 34 years old, with nodular sclerosis subtype, stage II disease, and both of them received 6 cycles of ABVD as a frontline therapy without radiation. The patient with stage IIA disease received radiation therapy for the relapse and now is in a remission; the other patient with stage IIB disease received salvage therapy with autologous stem cell transplantation abroad, since stem cell transplantation is not available in Armenia; he is lost from follow up since he left the country.

\section{Discussion}

Hodgkin lymphoma most frequently presents between 15 and 49 years of age, however people at any age can get that disease(DeSantis et al., 2014). In our study cohort we only examined adult patients, i.e. 18 years and older, and the median age was 28 years; in USA Hodgkin lymphoma is most commonly diagnosed among people from 20 to 34 years old, with a median age of 38 years; reports from other countries also showed similar results ("SEER 18 Stat Fact Sheets (2008-2012) - Hodgkin Lymphoma" 2015; Lee, Tan, and Feng 2005; Ramadas et al., 1994).

Studies from different parts of the world report HL is more common in males (Riyat 1992; Ramadas et al., 1994; Foss Abrahamsen et al., 1997; Siddiqui et al., 2006; Bosetti et al., 2009; Sant et al., 2010; Baharvand and Mortazavi 2014; Fadhil, Al-Nueimy, and Lazim, 2014; Sughayer et al., 2014; Torre et al., 2015), however, surprisingly, we see slightly more females and this need to be studied in a bigger cohort, whether it is an accidental finding or there are some correlations between gender and geographic location. This could be explained also by the male/female ratio in the whole adult population (15 - 64 years), which in Armenia, European Union, United States and Jordan is, respectively, 0.88; 1; 1.07 and 1.15 ("Gender Statistics. Highlights from 2012 World Development Report” 2012). Slightly higher incidence of HL in female was reported from some countries in Eastern Europe as well (Bosetti et al., 2009; Andjelic et al., 2014).

In the United States the most common form of HL is classic form (about 95\%) and lymphocyte - predominant form is rarely seen (5\%) (Swerdlow SH, Campo E, Harris NL 2008). In our clinic all patients presented with classic HL. In developed countries nodular sclerosis (NS) subtype is more frequently seen, however several studies from developing countries reported mixed cellularity (MC) subtype being predominant (Georgii et al., 1993; Ramadas et al., 1994; Lee, Tan, and Feng 2005; Siddiqui et al.. 2006; Olu-Eddo and Omoti 2011; Baharvand and Mortazavi 2014). Although Armenia is a developing country, but in our cohort NS was more than twice frequent than MC; approximately similar results recently were reported also from Iraq and Jordan (Yaqo et al., 2011; Fadhil, Al-Nueimy, and Lazim, 2014; Sughayer et al., 2014). In our cohort an interesting finding was higher incidence of lymphocyte rich variant, which is known to have an excellent outcome with current treatment strategies (Shimabukuro et al., 2005).

In developed countries, patients usually present with early stage disease (I, II), and in developing countries with advanced stage disease (III, IV). In our cohort 17 patients were with early stage disease (no stage I patient; only stage II) and 19 patients with advanced stage (III or IV) 
disease, which is similar to previously published results from other developing countries (Riyat, 1992; Ramadas et al., 1994; Siddiqui et al., 2006). This can be explained by the lack of population education about early cancer signs, gaps in diagnostics, psychological and financial issues (many patients, even after noticing early signs, tend to visit doctors at the last, because of the fear of cancer and also fear of not having enough financial resources to cover diagnosis and treatment). Another reason in the case of HL could be that because the clinical manifestation of the disease is not very specific, so many patients could be misdiagnosed for a long time period.

$8(22 \%)$ patients resided in the villages and other 28 (78\%) in the cities; from those 8 patients from villages $6(75 \%)$ presented with late stage disease, which can be due to less developed health care infrastructure and higher level of the poverty in the villages.

The healthcare system in Armenia is a remnant from the past Soviet Union system, and despite several reforms performed during last 25 years, many problems still are of significance. The total expenditure on health in Armenia is about $4.5 \%$ of GDP with a $150 \$$ healthcare expenditure per capita, while in the United States the health expenditure is respectively $17.9 \%$ of GDP and $8.895 \$$ per capita ("World Health Organization Global Health Expenditure Database 2010 - 2014" 2015). As a result the population cannot access all free services contained in the governmentguaranteed Basic Benefit Package and the alternative financing mechanisms are very limited or lacking. In Armenia out-of-pocket payments are more than half of the all health care costs (Hakobyan at al., 2006; Richardson 2013). Out of 36 patients, only $6(17 \%)$ of them were covered by the government-guaranteed Basic Benefit package, which includes the fees for the hospital service and labs. All patients paid for their chemotherapy drugs themselves, for 1 course of ABVD around 300 USD and for 1 course of BEACOPP around 600 USD, depending on the drug store they buy the drugs and deliver to the clinic. The hospital service fees are approximately 300 - 400 USD for 1 course of chemotherapy. As a result patients only for chemotherapy for HL usually spend from 4000 to 6000 USD, which is a big amount of money for a country with an average monthly salary of 350 USD, and the situation is even more difficult for the poorest households ("National Statistical Service of Republic of Armenia" 2015).

Although the number of patients involved in the study is small and the median follow-up time is just two years, this retrospective study shows that the treatment of Hodgkin lymphoma could be successfully organized also in resource-limited setting and that the epidemiology and outcomes of HL in Armenia possibly is reaching developed countries. Larger studies with longer follow-up are needed to confirm the findings of this study.

\section{References}

Andjelic B, Antic D, Jakovic L, et al (2014). A single institution experience on 314 newly diagnosed advanced hodgkin lymphoma patients: the role of ABVD in daily practice. Eur J Haematol, 93, 392-99.

Baharvand M, Mortazavi H (2014). Characteristics of Hodgkin lymphoma in a defined group of iranian pediatric patients. Asian Pac J of Cancer Prev, 15, 5167-69.

Bosetti C, Levi F, Ferlay J, et al (2009). The recent decline in mortality from hodgkin lymphomas in central and eastern europe. Ann Oncol, 20, 767-74.

Carbone P, Kaplan H, Musshoff K, et al (1971). Report of the committee on hodgkin's disease staging classification. Cancer Res, 31, 1860-61.

DeSantis C, Lin C, Mariotto A, et al (2014). Cancer Treatment and Survivorship Statistics. CA Cancer J Clin, 64, 252-71.

Dinand V, Arya L (2006). Epidemiology of childhood hodgkins disease: is it different in developing countries? Indian Pediatr, 43, 141-47.

Fadhil M, Al-Nueimy W, Lazim A (2014). Hodgkin's lymphoma. an immunohistochemical profile in Northern Iraq. Saudi Med J, 35, 448-53.

Foss Abrahamsen A, Egeland T, Hansen S, et al (1997). Hodgkin's disease in a national and hospital population: trends over 20 years. Eur J Cancer, 33, 2380-83.

Geller S, Taylor C (2013). Thomas hodgkin: the 'man' and 'his disease': humani nihil a se alienum putabit (nothing human was foreign to him). Virchows Arch, 463, 353-65.

Gender Statistics. Highlights from (2012). World Development Report (2012). [Online].

Georgii A, Fischer R, Hubner K, et al (1993). Classification of hodgkin's disease biopsies by a panel of four histopathologists. report of 1,140 patients from the German National Trial. Leuk Lymphoma, 9, 365-70.

Hakobyan T, Nazaretyan M, Makarova T, et al (2006). Armenia: health system review. Health Syst Transit, 8, 1-202.

Harris N (1999). Hodgkin's lymphomas: classification, diagnosis, and grading. Semin Hematol, 36, 220-32.

Hessissen L, Khtar R, Madani A, et al (2013). Improving the prognosis of pediatric hodgkin lymphoma in developing countries: a moroccan society of pediatric hematology and oncology study. Pediatr Blood Cancer, 60, 1464-69

Lee M, Tan T, Feng A (2005). Clinico-pathological study of hodgkin's lymphoma in a cancer center in Taiwan. Clin Lab Haematol, 27, 379-83.

Lister T, Crowther D, Sutcliffe S, et al (1989). Report of a committee convened to discuss the evaluation and staging of patients with hodgkin's disease: cotswolds meeting. $J$ Clin Oncol, 7, 1630-66.

Macfarlane G, Evstifeeva T, Boyle P, et al (1995). International patterns in the occurrence of hodgkin's disease in children and young adult males. Int J Cancer, 61, 165-69.

National Statistical Service of Republic of Armenia (2015). [Online].

NCCN Clinical Practice Guidelines in Oncology. Hodgkin Disease/Lymphoma (2008). Vol 2. [Online].

Olu-Eddo A, Omoti C (2011). Hodgkin lymphoma: clinicopathologic features in benin city, nigeria and update on its biology and classification. Niger J Clin Pract, 14, 440-44.

Ramadas K, Sankaranarayanan R, Nair M, et al (1994). Adult Hodgkin's disease in Kerala. Cancer, 73, 2213-17.

Richardson E (2013). Armenia: health system review. Health Syst Transit, 15, 1-99.

Riyat M (1992). Hodgkin's disease in Kenya. Cancer, 69, 1047-51.

Sant M, Allemani C, Tereanu C, et al (2010). Incidence of hematologic malignancies in europe by morphologic subtype: results of the haemacare project. Blood, 116, 3724-34.

SEER 18 Stat Fact Sheets (2008-2012) - Hodgkin lymphoma. [Online].

Sherief L, Elsafy U, Abdelkhalek E, et al (2015). Hodgkin lymphoma in childhood: clinicopathological features and 
Armen Avagyan et al

therapy outcome at 2 centers from a developing country. Med, 94, 670

Shimabukuro-Vornhagen A, Haverkamp H, Engert A (2005). Lymphocyte-rich classical Hodgkin's lymphoma: clinical presentation and treatment outcome in 100 patients treated within german hodgkin's study group trials. J Clin Oncol, 23, 5739-45.

Siddiqui N, Ayub B, Badar F, et al (2006). Hodgkin's lymphoma in Pakistan: a clinico-epidemiological study of 658 cases at a cancer center in Lahore. Asian Pac J Cancer Prev, 7, 651-55.

Sughayer M, Haddad H, Al-Yousef R, et al (2014). Epstein-barr virus and hodgkin lymphoma in Jordan. Hematol Oncol Stem Cell Ther, 7, 85-89.

Swerdlow S, Campo E, Harris N, et al (2008). WHO classification of tumours of haematopoietic and lymphoid tissues. IARC WHO Classification of Tumours, 2, 1-439.

Torre L, Bray F, Siegel R, et al (2015). Global Cancer Statistics, 2012. CA Cancer J Clin, 65, 87-108.

World Health Organization Global Health Expenditure Database 2010-2014 (2015). [Online].

Yaqo R , Hughson M, Sulayvani F, et al (2011). Malignant lymphoma in northern Iraq: a retrospective analysis of 270 cases according to the world health organization classification. Indian J Cancer, 48, 446-51 